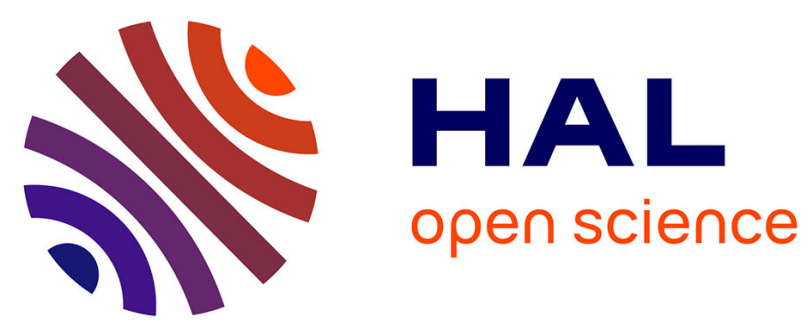

\title{
Transport properties and electronic density-of-states of Zn-doped colusite Cu26Cr2Ge6S32
}

Ventrapati Pavan Kumar, Sunanda Mitra, Gabin Guelou, Andrew R. Supka, P. Lemoine, Bernard Raveau, Rabih Al Rahal Al Orabi, Marco Fornari, Koichiro Suekuni, Emmanuel Guilmeau

\section{To cite this version:}

Ventrapati Pavan Kumar, Sunanda Mitra, Gabin Guelou, Andrew R. Supka, P. Lemoine, et al.. Transport properties and electronic density-of-states of Zn-doped colusite Cu26Cr2Ge6S32. Applied Physics Letters, 2020, 117 (17), pp.173902. 10.1063/5.0023712 . hal-03040544

\section{HAL Id: hal-03040544 https://hal.science/hal-03040544}

Submitted on 14 Dec 2020

HAL is a multi-disciplinary open access archive for the deposit and dissemination of scientific research documents, whether they are published or not. The documents may come from teaching and research institutions in France or abroad, or from public or private research centers.
L'archive ouverte pluridisciplinaire HAL, est destinée au dépôt et à la diffusion de documents scientifiques de niveau recherche, publiés ou non, émanant des établissements d'enseignement et de recherche français ou étrangers, des laboratoires publics ou privés. 


\section{Transport properties and electronic density-of-states of Zn-doped colusite $\mathrm{Cu}_{26} \mathrm{Cr}_{2} \mathrm{Ge}_{6} \mathrm{~S}_{32}$}

Ventrapati Pavan Kumar, ${ }^{1}$ Sunanda Mitra, ${ }^{1}$ Gabin Guélou, ${ }^{1}$ Andrew R. Supka, ${ }^{2}$ Pierric Lemoine, ${ }^{3}$ Bernard Raveau, ${ }^{1}$ Rabih Al Rahal Al Orabi, ${ }^{2,4}$ Marco Fornari, ${ }^{2,}{ }^{*}$ Koichiro Suekuni, ${ }^{5}$ Emmanuel Guilmeau, ${ }^{1, *}$

${ }^{1}$ CRISMAT, CNRS, Normandie Univ, ENSICAEN, UNICAEN, 14000 Caen, France

${ }^{2}$ Department of Physics and Science of Advanced Materials Program, Central Michigan University, Mt. Pleasant, MI 48859, USA

${ }^{3}$ Univ Rennes, CNRS, ISCR - UMR 6226, F-35000 Rennes, France

${ }^{4}$ Solvay, Design and Development of Functional Materials Department, Axel'One, 87 avenue des Frères Perret, 69192 Saint Fons, Cedex, France

${ }^{5}$ Department of Applied Science for Electronics and Materials, Interdisciplinary Graduate School of Engineering Sciences, Kyushu University, Kasuga, Fukuoka 816-8580, Japan

Corresponding authors : emmanuel.guilmeau@ensicaen.fr; fornalm@,cmich.edu

Keywords: thermoelectric, sulfide, colusite, off-stoichiometry, first-principle calculations 


\begin{abstract}
Thermoelectric colusites, one of the most recently identified and most promising family of complex $\mathrm{Cu}-\mathrm{S}$ materials, have quickly attracted significant attention based on their outstanding performance. Herein, we investigate the effect of zinc for copper substitution on the thermoelectric properties of the high-performance $\mathrm{Cr}-\mathrm{Ge}$ colusite, $\mathrm{Cu}_{26} \mathrm{Cr}_{2} \mathrm{Ge}_{6} \mathrm{~S}_{32}$. We discuss the striking impact of the aliovalent $\mathrm{Zn} / \mathrm{Cu}$ substitution on the charge carrier mobility and effective mass, and the consequences on the electrical and thermal transport properties. The investigation is supported by first-principles calculations of the electronic density-of-states of doped colusites. The theoretical study reveals the removal of the sharp features at the top of the valence manifold with the incorporation of $\mathrm{Zn}$ in the conductive network, with a strong reduction in the estimated relaxation time. These theoretical and experimental observations confirm the importance of disorder within the conductive network and the high sensitivity of the $\mathrm{Cu}-\mathrm{S}$ tetrahedral framework towards defects in high-performance thermoelectric colusites.
\end{abstract}


In recent times, upsurge in the demand for renewable energy resources has led to a greater focus on the thermoelectric technology, which enables the conversion of waste heat into electricity. ${ }^{1}$ The construction of marketable thermoelectric devices relies on the properties of the $p$ - and $n$ type components of the thermocouple and on several additional requirements such as environmental and cost constraints, both from a composition and/or a processing perspective..$^{2,3}$ For instance, tellurium-based materials notoriously exhibit good performances, but the scarcity of Te in the Earth's crust limits the thermoelectric technology to niche applications and uplifts the demand for other alternative Earth-abundant and non-toxic materials.

A common way to elucidate the efficiency of a thermoelectric material is by determining the dimensionless figure of merit $z T=S^{2} T / \rho \kappa$, where $T$ is the absolute temperature, $S$ the Seebeck coefficient, $\rho$ the electrical resistivity, and $\kappa$ the thermal conductivity. Promising figure of merit values, found over the last decade in sulfur-based materials, revived the interest in sulfides and led to the identification of new promising families of thermoelectric materials. ${ }^{4,5}$ In particular, several derivatives of natural copper-rich sulfide minerals, such as bornite $\mathrm{Cu}_{5} \mathrm{FeS}_{4},{ }^{6-9}$ tetrahedrite $\mathrm{Cu}_{12-x} \operatorname{Tr}_{\mathrm{x}} \mathrm{Sb}_{4} \mathrm{~S}_{13}(\operatorname{Tr}=\mathrm{Mn}, \mathrm{Fe}, \mathrm{Co}, \mathrm{Ni}, \mathrm{Zn}),{ }^{10-14}$ germanite derivative $\mathrm{Cu}_{22} \mathrm{Fe}_{8} \mathrm{Ge}_{4} \mathrm{~S}_{32},{ }^{15-17}$ stannoidite $\mathrm{Cu}_{8.5} \mathrm{Fe}_{2.5} \mathrm{Sn}_{2} \mathrm{~S}_{12},{ }^{18}$ mawsonite $\mathrm{Cu}_{6} \mathrm{Fe}_{2} \mathrm{SnS}_{8},{ }^{19-21}$ famatinite $\mathrm{Cu}_{3} \mathrm{SbS}_{4}{ }^{22}$ enargite $\mathrm{Cu}_{3} \mathrm{PS}_{4},{ }^{23}$ and mohite $\mathrm{Cu}_{2} \mathrm{SnS}_{3},{ }^{24}$ exhibit high performance $p$-type thermoelectric properties. In such compounds, the conducting $\mathrm{Cu}-\mathrm{S}$ framework, which defines the nature of the valence band, is mainly responsible for the behavior of the transport properties. ${ }^{25-27}$ Synthetic materials with the colusite structure such as $\mathrm{Cu}_{26} T_{2} M_{6} \mathrm{~S}_{32}(T=\mathrm{V}, \mathrm{Nb}$, Ta, Cr, Mo, W; $M=$ Ge, Sn) have gained considerable attention due to their high $z T$ values owing to a relatively high power factor $\left(P F=S^{2} / \rho\right)$ and low $\kappa_{\text {lat }}{ }^{26-35}$ High power factor values were recently achieved in colusites $\mathrm{Cu}_{26} T_{2} \mathrm{Ge}_{6} \mathrm{~S}_{32}\left(T=\mathrm{Cr}\right.$, Mo, W), ranging from $1.15 \mathrm{~mW} \mathrm{~m}{ }^{-1}$ $\mathrm{K}^{-2}$ at $700 \mathrm{~K}$ for $T=\mathrm{W}$ to a value of $1.94 \mathrm{~mW} \mathrm{~m}^{-1} \mathrm{~K}^{-2}$ for $T=\mathrm{Cr}^{26}$ Such exceptional electronic transport properties were explained by the nature of the interstitial $T$ cations forming mixed 
tetrahedral-octahedral $\left[\mathrm{TS}_{4}\right] \mathrm{Cu}_{6}$ complexes, which influence the conductive " $\mathrm{Cu}_{26} \mathrm{~S}_{32}$ " framework. In $\mathrm{Cu}_{26} \mathrm{Cr}_{2} \mathrm{Ge}_{6} \mathrm{~S}_{32}$, the smaller ionic size and the lower electronegativity of $\mathrm{Cr}^{6+}$ compared with other $T^{6+}$ cations lead to strong $T-\mathrm{Cu}$ interactions that do not perturb the conductive network significantly; this leads to outstanding power factors. We have learned from the isovalent substitution of $\mathrm{Cr}$ by $\mathrm{Mo}$ and $\mathrm{W}$ at the $T$ site in the $\mathrm{Cu}_{26} \mathrm{Cr}_{2-x}(\mathrm{Mo}, \mathrm{W})_{x} \mathrm{Ge}_{6} \mathrm{~S}_{32}$ series, that the disorder located at the $T$ site, illustrated by the cationic-size variance, induces a socalled size-mismatch effect in the mixed tetrahedral-octahedral complex that ultimately influences the transport properties. ${ }^{27}$ These results clearly demonstrate that the substitutions at the $T$ site in $\mathrm{Cu}_{26} \mathrm{Cr}_{2} \mathrm{Ge}_{6} \mathrm{~S}_{32}$ significantly and indirectly perturb the mobility of charge carriers in the $\mathrm{Cu}-\mathrm{S}$ conducting network, and lead to a decrease of the $P F$ values. Herein, we aimed to tune the charge carrier concentration and to optimize the thermoelectric performances by the aliovalent substitution of $\mathrm{Cu}$ by $\mathrm{Zn}$, without altering the nature of the $T$ site. The role of $\mathrm{Zn}$ as an electron donor is established and its influence on the thermoelectric properties of $\mathrm{Cu}_{26} \mathrm{Cr}_{2} \mathrm{Ge}_{6} \mathrm{~S}_{32}$ is discussed. We present here a complete study of the bulk properties of $\mathrm{Zn}$ doped $\mathrm{Cu}_{26} \mathrm{Cr}_{2} \mathrm{Ge}_{6} \mathrm{~S}_{32}$ colusite including the characterization of the electronic structures from first-principles calculations.

Powder X-ray diffraction (PXRD) patterns of the sintered compacts in the $\mathrm{Cu}_{26-x} \mathrm{Zn}_{x} \mathrm{Cr}_{2} \mathrm{Ge}_{6} \mathrm{~S}_{32}$ series $(x=0,0.5,1.0$ and 2.0) are displayed in Figure S1. PXRD data are consistent with the formation of a high purity colusite samples phase for all compositions, with the positions and intensities of the reflections in agreement with the reported structural analysis of the cubic $\mathrm{Cu}_{26} \mathrm{Cr}_{2} \mathrm{Ge}_{6} \mathrm{~S}_{32}$ phase (space group $P \overline{4} 3 n$ ). ${ }^{26,36}$ Only minor traces of $\mathrm{CuCrS}_{2}$ are found for the higher $\mathrm{Zn}$ content samples. Le Bail fits of the PXRD patterns revealed a systematic increase in the unit cell parameter with Zn content, from $a \approx 10.552$ (1) $\AA$ for $x=0$ to $a \approx 10.581$ (1) $\AA$ for $x=2$ (Inset of Figure S1). From a formal charge point of view, stoichiometric colusite is assumed to be $\left(\mathrm{Cu}^{+}\right)_{24}\left(\mathrm{Cu}^{2+}\right)_{2}\left(\mathrm{Cr}^{6+}\right)_{2}\left(\mathrm{Ge}^{4+}\right)_{6}\left(\mathrm{~S}^{2-}\right)_{32}$. In fact the mixed valence $\mathrm{Cu}^{+} / \mathrm{Cu}^{2+}$, which 
characterizes this sulfide, does not correspond to the coexistence of $\mathrm{Cu}^{2+}$ and $\mathrm{Cu}^{+}$cations but allows to express the copper framework as $\left[\mathrm{Cu}^{+}\right]_{26}$ with 2 holes per formula unit. The aliovalent substitution of two copper ions by another divalent ion such as $\mathrm{Zn}^{2+}$, without further charge modification leads to the fully compensated $\left(\mathrm{Cu}^{+}\right)_{24}\left(\mathrm{Zn}^{2+}\right)_{2}\left(\mathrm{Cr}^{6+}\right)_{2}\left(\mathrm{Ge}^{4+}\right)_{6}\left(\mathrm{~S}^{2-}\right)_{32}$ framework. With regard to the increase of the cell parameter $a$ with the $\mathrm{Zn}$ content, and the ionic radii of $\mathrm{Zn}^{2+}$ (i.e. $\left.0.60 \AA\right), \mathrm{Cu}^{+}$(i.e. $\left.0.60 \AA\right)$, and $\mathrm{Cu}^{2+}$ (i.e. $0.57 \AA$ ) in tetrahedral coordination, ${ }^{37}$ we can assume that $\mathrm{Zn}$ mainly substituted $\mathrm{Cu}$ in the structure. The nonlinear increase suggests that $\mathrm{Cu}$ is not fully substituted by $\mathrm{Zn}$ in the structure or that a slight stoichiometry deviation occurred, in agreement with the presence of $\mathrm{CuCrS}_{2}$ impurities. Additionally, no variation in the intensity of the superstructure diffraction peaks (at low angles) can be observed, suggesting that $\mathrm{Zn}$ atoms do not substitute for $\mathrm{Cr}$ in the $2 a$ position. However, we cannot exclude the possibility of $\mathrm{Zn}$ substitution on the Ge sites. First principles calculations give a slightly smaller lattice parameter for the undoped system ( $a=10.443 \AA)$ but match the small expansion induced by Zn doping (about $0.2 \%$ ). After structural relaxations, the $\mathrm{Cu}-\mathrm{S}$ tetrahedral network is minimally affected by the $\mathrm{Zn}$ substitution in agreement with the experimental data.

The SEM images of the fractured cross-sections of the sintered samples are displayed in Figure S2. The highly dense nature of the sintered samples is clear from the SEM images and is consistent with the determined relative density, greater than $95 \%$ of the theoretical value. The pristine and Zn-substituted samples show a homogeneous microstructure characterized by an isotropic grain shape and rather homogeneous grain sizes between 0.5 and $1 \mu \mathrm{m}$. No specific differences are observed between the four samples. EDS analyses (spots and frame) confirmed the homogeneous distribution of $\mathrm{Zn}$ in the samples (Table S1).

The electrical and thermal transport properties, over the temperature range 300-700 K, are displayed in Figure 1. Positive values of the Seebeck coefficient (Figure 1a) are measured for all compositions over the entire temperature range, confirming holes as dominant charge 
carriers. $S$ values increase monotonically with increasing temperature for all the compositions, representative of a degenerate semiconducting behavior. $S$ value increases gradually with the increase of $\mathrm{Zn}$ content, from $83 \mu \mathrm{V} \mathrm{K}^{-1}$ for $x=0$ to $146 \mu \mathrm{V} \mathrm{K}^{-1}$ for $x=2$ at $300 \mathrm{~K}$. The increase of $S$ with $\mathrm{Zn}$ content is consistent with the role of $\mathrm{Zn}$ as an electron donor as it replaces $\mathrm{Cu} .{ }^{29,38,39}$ $\mathrm{Zn}$ for $\mathrm{Cu}$ substitution leads to compensation of holes in the valence band which brings the Fermi level closer to the top of the valence band, where fewer carriers contribute to the higher Seebeck coefficient. Based on a single parabolic band model, the carrier concentrations $(p)$ were calculated from the Hall coefficient $R_{\mathrm{H}}$ using $p=1 / R_{\mathrm{H}} \cdot e$, where $e$ is the electron charge. The $p$ type carrier conduction behavior is confirmed from the positive values of the Hall coefficient. The temperature dependence of the carrier concentration, over $5 \mathrm{~K}-300 \mathrm{~K}$, is shown in Figure $\mathbf{S 3}$ for the $\mathrm{Cu}_{26-\mathrm{x}} \mathrm{Zn}_{\mathrm{x}} \mathrm{Cr}_{2} \mathrm{Ge}_{6} \mathrm{~S}_{32}$ series. The $n$ value does not vary significantly with the increase in temperature, confirming a degenerate semiconducting behavior. The carrier concentration decreases with increasing zinc content from $4.5 \times 10^{21} \mathrm{~cm}^{-3}$ for $x=0$ to $2.6 \times 10^{21} \mathrm{~cm}^{-3}$ for $x=$ 2.0; this is in reasonable agreement with the results of first principles calculations shown below. This behavior is also consistent with the increase of the electrical resistivity with $\mathrm{Zn}$ content, from $0.46 \mathrm{~m} \Omega \mathrm{cm}$ for $x=0$ to $6.0 \mathrm{~m} \Omega \mathrm{cm}$ for $x=2$, at $300 \mathrm{~K}$ (Figure 1b). For $x=2$, an overall flattening of the temperature dependence is observed, suggesting that this chemical composition is close to the metal-like to semiconductor transition. Indeed, according to the charge balance, we can expect a semiconducting behavior for $x=2$. As already discussed above, this suggests that the $\mathrm{Zn}$ content in the structure is slightly smaller than the nominal one or that a slight stoichiometric deviation exists.

The band structure of pristine $\mathrm{Cu}_{26} \mathrm{Cr}_{2} \mathrm{Ge}_{6} \mathrm{~S}_{32}$ (Ref. ${ }^{26}$ and Figure S4) exhibits a flat band at the top of the valence manifold between the $\Gamma$ and $M$ high-symmetry points. The density of states (DOS) has a sharp feature at the band edge but the Fermi level in this $p$-type $\mathrm{Cu}_{26} \mathrm{Cr}_{2} \mathrm{Ge}_{6} \mathrm{~S}_{32}$ is $80 \mathrm{meV}$ below the top of the valence band. In Figure 2, we report the DOS for several models 
for $\mathrm{Cu}_{26-x} \mathrm{Zn}_{x} \mathrm{Cr}_{2} \mathrm{Ge}_{6} \mathrm{~S}_{32}$ with $x=1$ and $x=2$. The substitution of $\mathrm{Cu}$ with $\mathrm{Zn}$ in $6 d$, $8 e$, and $12 f$ Wyckoff positions, of course, breaks the symmetry and lifts several degeneracies with the result of removing the sharp features at the top of the valence manifold as well as distribution of relevant electronic states and carrier concentration. Due to rearrangement of the energy levels, in the models we studied, the Fermi level shifts to $100 \pm 20 \mathrm{meV}$ below the top of the valence band for $x=1$. A semiconductor band structure with a forbidden energy gap larger than 200 meV is obtained with $x=2$; as mentioned, sharp features in the DOS at the band edge disappear in both cases pointing to a reduction of the effective mass. In order to assess the effect of disorder, we have aligned the DOS in Figure 2 using the low-lying levels of Ge which are negligibly perturbed by $\mathrm{Zn}$ addition. Overall, the substitution smoothens out the top of the valence band.

Both the Seebeck coefficient and the electrical resistivity increase with Zn content, resulting in a power factor that steadily decreases with increasing $\mathrm{Zn}$ content over the whole investigated temperature range (Figure 1e). Nonetheless, the electrical performance remains high for a copper-based sulfide with a maximum $P F$ of $1.9 \mathrm{~mW} \mathrm{~m}^{-1} \mathrm{~K}^{-2}$ and $1.2 \mathrm{~mW} \mathrm{~m}^{-1} \mathrm{~K}^{-2}$ at $700 \mathrm{~K}$ for the pristine $\mathrm{Cu}_{26} \mathrm{Cr}_{2} \mathrm{Ge}_{6} \mathrm{~S}_{32}$ and $x=0.5$, respectively. The decrease in $P F$ is linked to the decrease in Hall carrier mobility from $2.41 \mathrm{~cm}^{2} \mathrm{~V}^{-1} \mathrm{~s}^{-1}$ for $x=0$ to $0.39 \mathrm{~cm}^{2} \mathrm{~V}^{-1} \mathrm{~s}^{-1}$ for $x=2$ at room temperature (Figure S5); nearly an order of magnitude decrease is observed for the composition with the maximum $\mathrm{Zn}$ content. The decrease in hole mobility with the increase of $\mathrm{Zn}$ content is mainly attributed to point defects in the $\mathrm{Cu}-\mathrm{S}$ conductive network and/or to the presence of $\mathrm{CuCrS}_{2}$ impurities $(x=2)$. These results indicate that both the decreases in carrier concentration and carrier mobility with the increase of $\mathrm{Zn}$ content are responsible for the strong increase in the resistivity values. The negative temperature coefficient of Hall carrier mobility for all the measured compositions clearly indicates that the acoustic phonon scattering is the dominant scattering phenomenon. 
In order to separate the contribution of electron scattering from band structure features, we evaluated the effective mass of carriers at RT $\left(m^{*}\right)$. By considering the single parabolic band (SPB) model, with the approximation of acoustic phonon scattering $(r=-1 / 2), m^{*}$ can be derived according to equations (1) to (4) using the measured $S$ and carrier concentration $(n)$.

$$
\begin{gathered}
m^{*}=\frac{h^{2}}{2 k_{B} T}\left[\frac{n}{4 \pi F_{1 / 2}(\eta)}\right]^{2 / 3} \\
S= \pm \frac{k_{B}}{e}\left(\frac{(r+5 / 2) F_{r+3 / 2}(\eta)}{(r+3 / 2) F_{r+1 / 2}(\eta)}-\eta\right) \\
F_{n}(\eta)=\int_{0}^{\infty} \frac{\chi^{n}}{1+e^{\chi-\eta}} d \chi \\
\eta=\frac{E_{f}}{k_{B} T}
\end{gathered}
$$

Where $\eta$ is the reduced Fermi energy, $F_{n}(\eta)$ is the $\mathrm{n}^{\text {th }}$ order of Fermi integral, $k_{\mathrm{B}}$ is the Boltzmann constant, $e$ is the electron charge, $E_{F}$ is the Fermi energy, $h$ is the Planck constant, and $r$ is the scattering factor. The value of $\eta$ is obtained from fitting of Seebeck coefficient $v s$ temperature data. The carrier effective mass $m^{*}$ decreases as the $\mathrm{Zn}$ concentration increases from $7.1 m_{0}$ for $x=0$ to $6.35 m_{0}$ for $x=1$ and $4.7 m_{0}$ for $x=2$ respectively. The variations of the DOS at the top of the valence band are qualitatively compatible with the reduction of the experimental effective mass. As a result, the introduction of $\mathrm{Zn}$ decreases simultaneously the carrier mobility and effective mass suggesting that the scattering time is decreased by the structural disorder on the $\mathrm{Cu}-\mathrm{S}$ conductive framework. Our estimated relaxation times (assumed to be constant) at room temperature is dropping to one tenth of the value of the pristine sample.

The temperature dependences of the thermal conductivity in the $\mathrm{Cu}_{26-x} \mathrm{Zn}_{x} \mathrm{Cr}_{2} \mathrm{Ge}_{6} \mathrm{~S}_{32}$ series are shown in Figure 1c. A typical room temperature value of $\sim 2.85 \mathrm{~W} \mathrm{~m}^{-1} \mathrm{~K}^{-1}$ is observed for 
$\mathrm{Cu}_{26} \mathrm{Cr}_{2} \mathrm{Ge}_{6} \mathrm{~S}_{32}$, which decreases to around $1.6 \mathrm{~W} \mathrm{~m}^{-1} \mathrm{~K}^{-1}$ at $700 \mathrm{~K}$. This $\mathrm{RT}$ value is comparable to the value of $2.9 \mathrm{~W} \mathrm{~m}^{-1} \mathrm{~K}^{-1}$ observed by Bourgès et al. in colusite $\mathrm{Cu}_{26} \mathrm{~V}_{2} \mathrm{Sn}_{6} \mathrm{~S}_{32 .}{ }^{38}$ The thermal conductivity decreases with varying the $\mathrm{Zn}$ content which reaches the lowest value of $1.94 \mathrm{~W}$ $\mathrm{m}^{-1} \mathrm{~K}^{-1}$ at RT for $x=2$. Such a decrease in the thermal conductivity is mainly caused by a decrease in the electronic contribution to the thermal conductivity $\left(\kappa_{e}\right)$. The lattice thermal conductivity $\left(\kappa_{L}\right)$ does not seem to vary significantly with $\mathrm{Zn}$ content, with room temperature values between 1.6 and $1.86 \mathrm{~W} \mathrm{~m}^{-1} \mathrm{~K}^{-1}$ (Figure 1d). Such behavior can be expected, since the mass contrast between $\mathrm{Cu}$ and $\mathrm{Zn}$ is minimal and therefore point defect scattering, due to the mass disorder, can be assumed to be negligible. Note that the larger values in Zn-doped compounds at high temperature can be induced by an underestimation of the electronic contribution from the Wiedemann-Franz law due to the significant increase in electrical resistivity. All the compositions are following a 1/T dependence, which indicates that Umklapp process is responsible for the majority of phonon scattering.

Temperature dependences of the dimensionless thermoelectric figure of merit, $z T$, in the $\mathrm{Cu}_{26-}$ ${ }_{x} \mathrm{Zn}_{x} \mathrm{Cr}_{2} \mathrm{Ge}_{6} \mathrm{~S}_{32}$ series are displayed in Figure 1f. The $z T$ values for all samples increase monotonically with temperature. The thermoelectric figure of merit decreases with increasing $\mathrm{Zn}$ content and reaches a maximum value of $\sim 0.7$ for $x=1.0$ at $700 \mathrm{~K}$ among the $\mathrm{Zn}$ substituted compositions. The decrease of $z T$ with the increase of $\mathrm{Zn}$ content is a direct consequence of the strong reductions in electrical conductivity and power factor values, attributed to a loss of carrier mobility within the conductive network.

In conclusion, we have reported a detailed study of the thermoelectric properties of $\mathrm{Cu}_{26}$ ${ }_{x} \mathrm{Zn}_{\mathrm{x}} \mathrm{Cr}_{2} \mathrm{Ge}_{6} \mathrm{~S}_{32}$ samples measured over temperature range of $300-700 \mathrm{~K}$. The increase in lattice parameter with $x$ confirms the substitution of $\mathrm{Zn}$ for $\mathrm{Cu}$ in the colusite structure. This study indicates that the aliovalent substitution of copper with zinc deteriorates the thermoelectric properties of $\mathrm{Cu}_{26} \mathrm{Cr}_{2} \mathrm{Ge}_{6} \mathrm{~S}_{32}$ when compared to the isovalent substitution at the $T$ site. The $\mathrm{Zn}$ 
for $\mathrm{Cu}$ substitution in $\mathrm{Cu}_{26} \mathrm{Cr}_{2} \mathrm{Ge}_{6} \mathrm{~S}_{32}$ provides additional electrons into the system, which result in a reduction of the charge carrier concentration as well as a decrease in the hole mobility. These experimental results are rationalized with an effect of the $\mathrm{Zn}$ substitution on the band structure (and effective masses) and a decrease in the electron relaxation time due to the disorder on the $\mathrm{Cu}$ sublattice. The lattice thermal conductivity, very similar for all $\mathrm{Zn}$-substituted compositions, ranges around $\sim 0.75 \mathrm{~W} \mathrm{~m}^{-1} \mathrm{~K}^{-1}$ at $700 \mathrm{~K}$, resulting in a maximum $z T$ of 0.7 for $x=1.0$ at $700 \mathrm{~K}$. Interestingly, these results provide evidence that the introduction of point defects in the $\mathrm{Cu}-\mathrm{S}$ conductive network strongly alters the electronic transport properties with a strong reduction in carrier mobility and carrier concentration.

\section{AUTHOR'S CONTRIBUTIONS}

All authors contributed equally to this work.

\section{SUPPLEMENTARY INFORMATION}

Experimental section (synthesis, characterization techniques), PXRD patterns of the $\mathrm{Cu}_{26-}$ ${ }_{x} \mathrm{Zn}_{x} \mathrm{Cr}_{2} \mathrm{Ge}_{6} \mathrm{~S}_{32}$ series $(x=0,0.5,1.0$ and 2.0), SEM images of the fractured cross-sections for a) $x=0, \mathrm{~b}) x=0.5$, c) $x=1.0$ and d) $x=2.0$ respectively, temperature dependence of the carrier concentration ( $n$ ) in the $\mathrm{Cu}_{26-x} \mathrm{Zn}_{x} \mathrm{Cr}_{2} \mathrm{Ge}_{6} \mathrm{~S}_{32}$ series ( $x=0,1.0$ and 2.0), band structure and projected density of states of pristine colusite $\mathrm{Cu}_{26} \mathrm{Cr}_{2} \mathrm{Ge}_{6} \mathrm{~S}_{32}$ computed with first principles density functional theory methods, temperature dependence of the Hall mobility in the $\mathrm{Cu}_{26}$ ${ }_{x} \mathrm{Zn}_{x} \mathrm{Cr}_{2} \mathrm{Ge}_{6} \mathrm{~S}_{32}$ series $(x=0,1.0$ and 2.0$)$, structural models used for calculations.

\section{ACKNOWLEDGEMENTS}


The authors would like to thank Christelle Bilot and Jerôme Lecourt for technical support. This work was supported by LABEX EMC3, CARNOT ESP, FEDER, Institut CARNOT ESP, Normandy Region and the French Agence Nationale de la Recherche (ANR) through the programs Energy Challenge for Secure, Clean and Efficient Energy (Challenge 2, 2015, ANR15-CE05-0027).

\section{DATA AVAILABILITY STATEMENTS}

The data that supports the findings of this study are available within the article and its supplementary material. 


\section{References:}

${ }^{1}$ D.M. Rowe, Thermoelectrics Handbook: Macro to Nano, ed. D. M. (CRC Press, Boca Raton, FL, 2006).

${ }^{2}$ X. Shi, J. Zou, and Z. Chen, Chem. Rev. (2020).

${ }^{3}$ R. Freer and A. V Powell, J. Mater. Chem. C 8, 441 (2020).

${ }^{4}$ A. V Powell, J. Appl. Phys. 126, 100901 (2019).

${ }^{5}$ S. Hébert, D. Berthebaud, R. Daou, Y. Bréard, D. Pelloquin, E. Guilmeau, F. Gascoin, O. Lebedev, and A. Maignan, J. Phys. Condens. Matter 28, (2016).

${ }^{6}$ P. Qiu, T. Zhang, Y. Qiu, X. Shi, and L. Chen, Energy Environ. Sci. 7, 4000 (2014).

${ }^{7}$ G. Guélou, A. V. Powell, and P. Vaqueiro, J. Mater. Chem. C 3, 10624 (2015).

${ }^{8}$ V. Pavan Kumar, T. Barbier, P. Lemoine, B. Raveau, V. Nassif, and E. Guilmeau, Dalt. Trans. 46, 2174 (2017).

${ }^{9}$ S.O.J. Long, A. V Powell, P. Vaqueiro, and S. Hull, Chem. Mater. 30, 456 (2018).

${ }^{10}$ X. Lu, D.T. Morelli, Y. Xia, F. Zhou, V. Ozolins, H. Chi, X. Zhou, and C. Uher, Adv. Energy Mater. 3, 342 (2013).

${ }^{11}$ K. Suekuni, K. Tsuruta, T. Ariga, and M. Koyano, Appl. Phys. Express 5, 051201 (2012).

${ }^{12}$ K. Suekuni, K. Tsuruta, M. Kunii, H. Nishiate, E. Nishibori, S. Maki, M. Ohta, A. Yamamoto, and M. Koyano, J. Appl. Phys. 113, 043712 (2013).

${ }^{13}$ T. Barbier, P. Lemoine, S. Gascoin, O.I. Lebedev, A. Kaltzoglou, P. Vaqueiro, A. V. Powell, R.I. Smith, and E. Guilmeau, J. Alloys Compd. 634, 253 (2015).

${ }^{14}$ R. Chetty, A. Bali, and R.C. Mallik, J. Mater. Chem. C 3, 12364 (2015). 
${ }^{15}$ V. Pavan Kumar, L. Paradis-Fortin, P. Lemoine, V. Caignaert, B. Raveau, B. Malaman, G. Le Caër, S. Cordier, and E. Guilmeau, Inorg. Chem. 56, 13376 (2017).

${ }^{16}$ L. Paradis-Fortin, G. Guélou, V. Pavan Kumar, P. Lemoine, C. Prestipino, O. MerdrignacConanec, G.R. Durand, S. Cordier, O.I. Lebedev, and E. Guilmeau, J. Alloys Compd. 831, 154767 (2020).

${ }^{17}$ V. Pavan Kumar, L. Paradis-Fortin, P. Lemoine, G. Le Caër, B. Malaman, P. Boullay, B. Raveau, G. Guélou, and E. Guilmeau, ACS Appl. Energy Mater. 2, 7679 (2019).

${ }^{18}$ V. Pavan Kumar, T. Barbier, V. Caignaert, B. Raveau, R. Daou, B. Malaman, G. Le Caër, P. Lemoine, and E. Guilmeau, J. Phys. Chem. C 121, 16454 (2017).

${ }^{19}$ R. Zhang, K. Chen, B. Du, and M.J. Reece, J. Mater. Chem. A 5, 5013 (2017).

${ }^{20}$ P. Baláž, M. Hegedüs, M. Reece, R. Zhang, I. Škorvánek, J. Briančin, M. Baláž, M.

Tešinský, and M. Achimovičová, J. Electron. Mater. 48, 1846 (2019).

${ }^{21}$ I. Siloi, M. Fornari, S. Curtarolo, M. Buongiorno Nardelli, P. Vaqueiro, and M. Fornari, ACS Appl. Energy Mater. 2, 8068 (2019).

${ }^{22}$ T. Tanishita, K. Suekuni, H. Nishiate, C.-H. Lee, and M. Ohtaki, Phys. Chem. Chem. Phys. 22, 2081 (2020).

${ }^{23}$ T. Tanimoto, K. Suekuni, T. Tanishita, H. Usui, T. Tadano, T. Kamei, H. Saito, H. Nishiate, C.H. Lee, K. Kuroki, and M. Ohtaki, Adv. Funct. Mater. 30, 2000973 (2020).

${ }^{24}$ Y. Shen, C. Li, R. Huang, R. Tian, Y. Ye, L. Pan, K. Koumoto, R. Zhang, C. Wan, and Y. Wang, Sci. Rep. 6, 32501 (2016).

${ }^{25}$ L. Xi, Y.B. Zhang, X.Y. Shi, J. Yang, X. Shi, L.D. Chen, W. Zhang, J.H. Yang, and D.J. Singh, Phys. Rev. B 86, 155201 (2012). 
${ }^{26}$ V. Pavan Kumar, A.R. Supka, P. Lemoine, O.I. Lebedev, B. Raveau, K. Suekuni, V. Nassif, R. Al Rahal Al Orabi, M. Fornari, and E. Guilmeau, Adv. Energy Mater. 9, 1803249 (2019).

${ }^{27}$ V. Pavan Kumar, G. Guélou, P. Lemoine, B. Raveau, A.R. Supka, R. Al Rahal Al Orabi, M. Fornari, K. Suekuni, and E. Guilmeau, Angew. Chemie - Int. Ed. 58, 15455 (2019).

${ }^{28}$ K. Suekuni, F.S. Kim, H. Nishiate, M. Ohta, H.I. Tanaka, and T. Takabatake, Appl. Phys. Lett. 105, 132107 (2014).

${ }^{29}$ K. Suekuni, F.S. Kim, and T. Takabatake, J. Appl. Phys. 116, 063706 (2014).

${ }^{30}$ C. Bourgès, Y. Bouyrie, A.R. Supka, R. Al Rahal Al Orabi, P. Lemoine, O.I. Lebedev, M. Ohta, K. Suekuni, V. Nassif, V. Hardy, R. Daou, Y. Miyazaki, M. Fornari, and E. Guilmeau, J. Am. Chem. Soc. 140, 2186 (2018).

${ }^{31}$ Y. Kikuchi, Y. Bouyrie, M. Ohta, K. Suekuni, M. Aihara, and T. Takabatake, J. Mater. Chem. A 4, 15207 (2016).

${ }^{32}$ C. Candolfi, G. Guélou, C. Bourgès, A.R. Supka, R. Al Rahal Al Orabi, M. Fornari, B. Malaman, G. Le Caër, P. Lemoine, V. Hardy, J. Zanotti, R. Chetty, M. Ohta, K. Suekuni, and E. Guilmeau, Phys. Rev. Mater. 4, 025404 (2020).

${ }^{33}$ K. Suekuni, Y. Shimizu, E. Nishibori, H. Kasai, H. Saito, D. Yoshimoto, K. Hashikuni, Y. Bouyrie, R. Chetty, M. Ohta, E. Guilmeau, T. Takabatake, K. Watanabe, and M. Ohtaki, J. Mater. Chem. A 7, 228 (2019).

${ }^{34}$ G. Guélou, V.P. Kumar, A. Bourhim, P. Lemoine, B. Raveau, A. Supka, O.I. Lebedev, R. Al Rahal Al Orabi, M. Fornari, K. Suekuni, and E. Guilmeau, ACS Appl. Energy Mater. 3, 4180 (2020).

${ }^{35}$ G. Guélou, C. Couder, A. Bourhim, O.I. Lebedev, N. Daneu, F. Appert, J. Juraszek, P. Lemoine, L. Segreto, and E. Guilmeau, Acta Mater. 195, 229 (2020). 
${ }^{36}$ P. Lemoine, V. Pavan Kumar, G. Guélou, V. Nassif, B. Raveau, and E. Guilmeau, Chem. Mater. 32, 830 (2020).

${ }^{37}$ R.D. Shannon, Acta Crystallogr. Sect. A 32, 751 (1976).

${ }^{38}$ C. Bourgès, M. Gilmas, P. Lemoine, N. Mordvinova, O.I. Lebedev, E. Hug, V.M. Nassif, B. Malaman, R. Daou, and E. Guilmeau, J. Mater. Chem. C 4, 7455 (2016).

${ }^{39}$ X. Lu, D.T. Morelli, Y. Xia, and V. Ozolins, Chem. Mater. 27, 408 (2015). 


\section{Figure captions}

Figure 1. Temperature dependence of the a) Seebeck coefficient $(S)$, b) electrical resistivity $(\rho)$, c) thermal conductivity $(\kappa)$, d) lattice thermal conductivity $\left(\kappa_{L}\right)$, e) power factor $(P F)$, and f) figure of merit $z T$ in the $\mathrm{Cu}_{26-x} \mathrm{Zn}_{x} \mathrm{Cr}_{2} \mathrm{Ge}_{6} \mathrm{~S}_{32}$ series.

Figure 2. Electronic density of states of pristine colusite $\mathrm{Cu}_{26} \mathrm{Cr}_{2} \mathrm{Ge}_{6} \mathrm{~S}_{32}$ (top panel) and with $\mathrm{Zn}$ doping. In the middle panel, the calculations have been performed by replacing one $\mathrm{Cu}$ atom in $8 e$ (orange), $6 d$, and $12 f$ with one $\mathrm{Zn}$ atom. In the bottom panel three different configurations with $\mathrm{Zn}$ atoms in $12 f$ and $6 d, 12 f$ and $8 e$, or $8 e$ and $6 d$ respectively. Dashed line corresponds to weighted averages. A metal-like to semiconductor transition occurs with increasing $\mathrm{Zn}$ concentration from $x=0$ to $x=2$. 

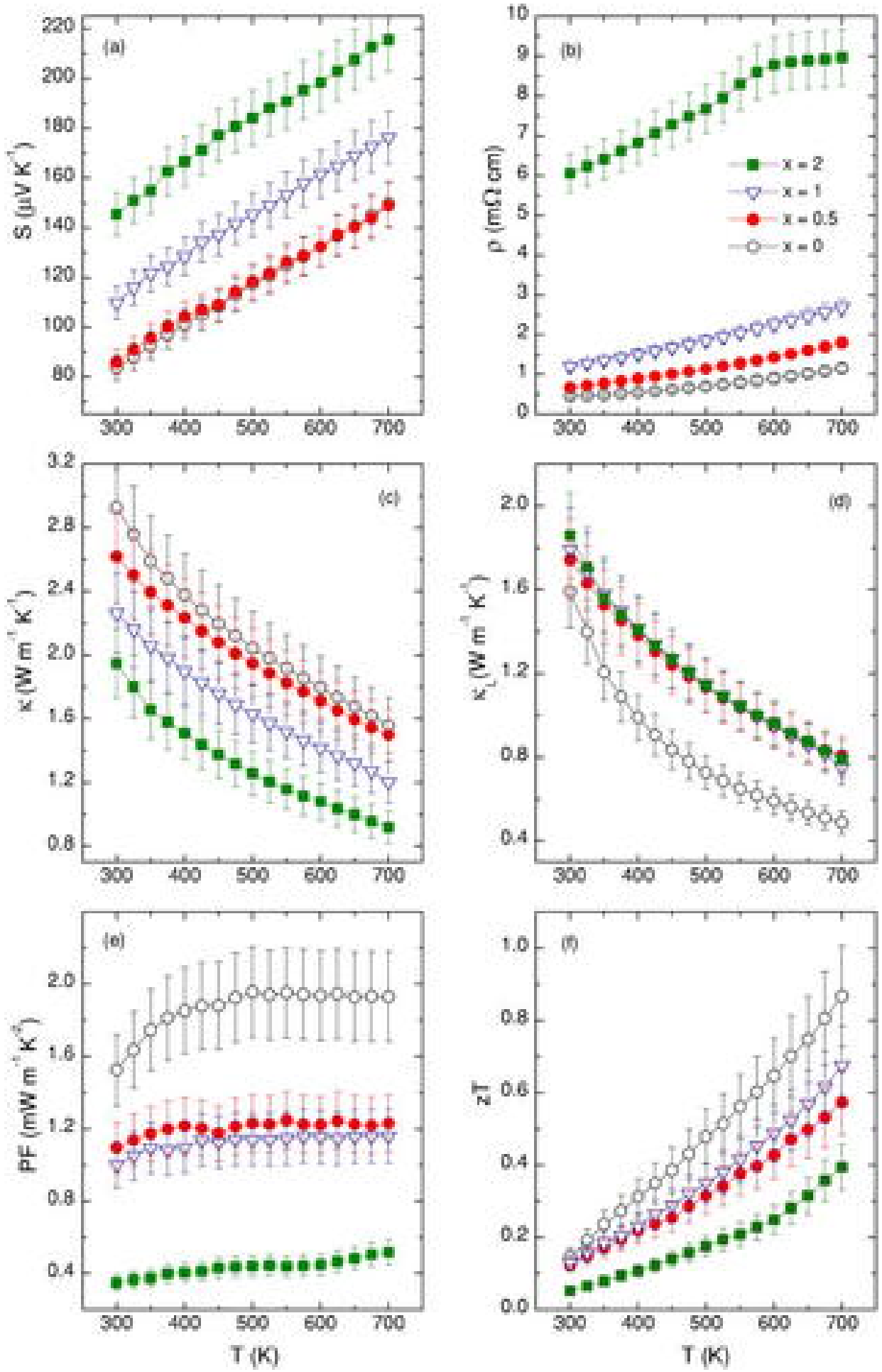


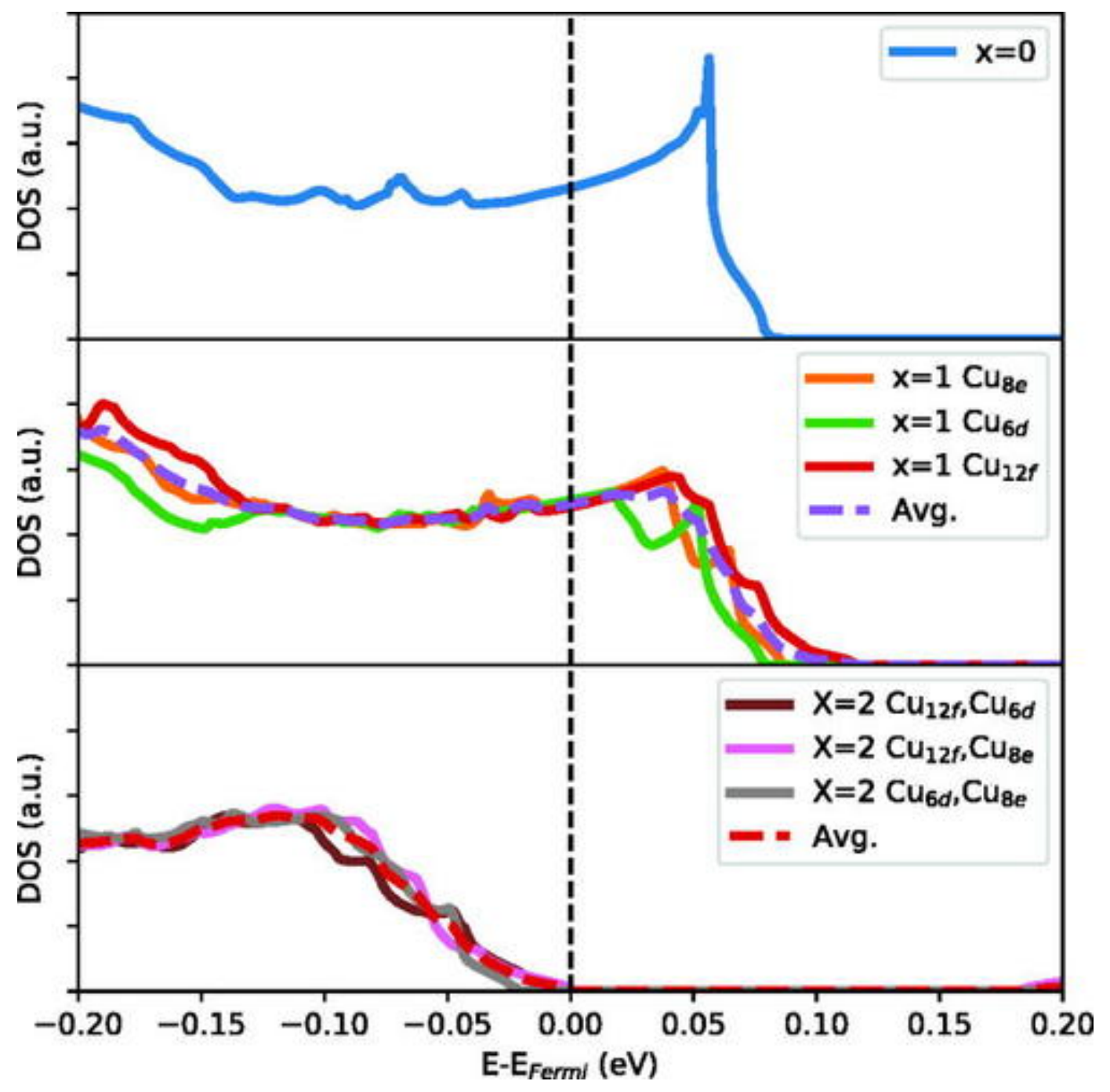

